\title{
Valuation in the environmental policy process
}

\author{
WILLIAM ASCHER* \& TODDI STEELMAN** \\ ${ }^{*}$ Claremont McKenna College \\ ** North Carolina State University
}

\begin{abstract}
Expert valuation, a process used to determine how much stakeholders value eco-system aspects, places experts as intermediaries for public-preference input into the environmental policy process. While the rise and refinement of expert valuation might capture ecosystem values more comprehensively, two dilemmas are also worth of consideration: (1) will expert valuation and benefit cost analysis supplant democratic expression; and (2) will refinement of expert valuation still leave the ecosystem under valued? This article reorients the current problem from focusing on the need to refine methods to capture more ecosystem benefits to consider how valuation can contribute to a set of more democratic processes that allow the public to contribute to and consider a broader range of policy options.
\end{abstract}

\section{Introduction}

Citizens have many modes of conveying their preferences in the environmental policy process, ranging from speaking up at town meetings and registering complaints about draft forestry plans, to voting for referendum proposals and candidates for elected office. However, one mode, which we will label expert valuation, is increasingly privileged through both regulatory mandate and scientific aura. Using a range of methods tied to econometric analysis or survey techniques, this form of valuation puts citizens in the position of research subjects rather than participants. It places technical experts between citizens and policymakers, ignoring citizen policy preferences by focusing instead on their values for outcomes presumed to come from various policy options. While the specialists working toward developing more comprehensive valuation techniques believe that they are contributing to a fuller appreciation of ecosystems and ecosystem services, the role of the experts as intermediaries also runs the risk of under-representing less tangible eco-system values. This bias arises because valuation experts may have to protect their professional standing by relegating these values to a status likely to have little influence on policy choices. Finally, the refinement of expert valuation undermines alternative decision-making claims, such as the assertion of rights, due to the increasing legitimacy of conventional benefit-cost analysis as the preferred decision-making paradigm for environmental policies. In short, the rise of expert valuation in the environmental policy process raises two dilemmas worthy of consideration. These are: (1) will valuation and benefit cost analysis supplant democratic expression; and (2) will refinement of expert valuation still leave the ecosystem under valued? Expert valuation, clearly the most "technocratic" vehicle for conveying public preferences, may preempt more robust forms of public participation in environmental policymaking and present policymakers with a particularly narrow sense of the public interest and what the public wants.

These issues have another side, though, that makes understanding the role of expert valuation much more complicated. John Loomis, among others, has argued that expert valuation contributes to democratic practice by providing a channel, albeit a passive 
one, for the values of "ordinary citizens." He argues that:

[w] ithout valuation studies, only those with sufficiently concentrated costs or benefits who attend hearings and committee meetings or make large campaign contributions will be heard. Valuation studies have the potential to provide an effective way to diminish the often bemoaned role of 'special interests' in the current policy process. (Loomis, 2000: p. 343)

Some valuation advocates have also argued that without expert valuation, environmental considerations would be given short shrift in the analysis of policies with environmental and conservation impacts. Valuation can demonstrate that people do value eco-systems, or at least that many people do. It can be argued that the absence of information about these values might leave the field to only narrowly conceived economic concerns.

Rather than take a position of condemning or applauding the rise of expert valuation, we take the more tentative - but hopefully more useful - position of posing this rise as an important trend that may have positive or negative impacts, depending on how related technical and policy issues are managed. Trends are emerging patterns with some potential for positive or negative effects on human welfare and dignity. Identifying trends can make policy analysis and interventions more sensitive to emerging risks and opportunities and patterns of expectations without a dogmatic prediction of the inevitability of particular outcomes. Indeed, predicting important outcomes implies the irrelevance of present and future choice.

The implications of the rise of expert valuation can be viewed as outcomes to be shaped rather than to be predicted. We will raise two dilemmas involved with expert valuation; how policymakers and experts address these dilemmas will be important in determining whether the impacts of expert valuation turn out well or badly. Equally important, we can put the rise of expert valuation in the context of two broader trends: the rise of formal benefit-cost analysis, and the even broader trend that Harold D. Lasswell labeled the "revolution of modernizing intellectuals," a pattern that he posed in 1965 to highlight the relationship between the interests of the emerging scientific elite and their impact on the content of policy inputs and outcomes. The trend emphasizes that the increased influence of any particular scientific, symbol-manipulating elite ${ }^{1}$ will shape policy outcomes, in part because such an elite will inevitably have distinctive values and interests (Lasswell, 1965: pp. 85-86). By assessing the rise of expert valuation within the rise of formal benefit-cost analysis and the revolution of modernizing intellectuals, we hope to shift the debate from focusing on the need to refine methods of benefit cost analysis to capture more ecosystem benefits to concentrate on more democratic processes that can adequately represent the range of values possessed by the active public to make policy in the common interest.

\section{The rise of valuation as a public preference vehicle}

Expert valuation of public preferences is increasingly entrenched as a policy input. In the United States, President Ronald Reagan's 1981 Executive Order, "Federal 
Regulation," required a Regulatory Impact Analysis (RIA) of proposed "major" federal regulations. The Order covered regulations with an annual effect on the economy of $\$ 100$ million or greater, those causing significant increases in costs or prices, and those having important adverse effects on competition, investment, productivity, employment or the international competitive position of firms in the United States. Net benefits of proposed regulations were to be quantified to the extent feasible (Smith, 1984). President Bill Clinton's 1993 Executive Order 12866, "Regulatory Planning and Review," (Federal Register, Vol. 58, October 4, 1993) required all newly proposed regulations to undergo an analysis of benefits and costs, to be monitored by the Office of Management and Budget's Office of Information and Regulatory Affairs (OIRA). All subsequent directives on how to implement this requirement emphasize the centrality of valuation in the calculation of benefit-cost assessments (OIRA, 2003).

The evolution of these executive orders reflects a growing appreciation of the need to avoid a narrow economic definition of costs and benefits. This can be viewed as a reaction against the original intent of requiring benefit-cost analysis, namely to restrict regulation by requiring stricter economic tests. Nevertheless, the call for an analysis of benefits and costs is clearly a call for benefit-cost analysis, a specific economic approach that requires the monetization of benefits and costs. In Europe, the expansion of environmental concern has prompted many efforts to develop and implement quite similar valuation techniques as inputs to industrial strategy as well as environmental policymaking (See Navrud, 1992). Through the efforts of international organizations such as the Food and Agriculture Organization, the World Bank and the regional development banks, as well as bilateral donors, many developing countries have been incorporating valuation in project and program appraisal methods (e.g., Food and Agriculture Organization of the United Nations, 2000; Silva and Pagiola, 2003). While the valuation-based assessment of net benefits of policy options rarely if ever dictates the policy choice in a formal sense, these assessments are becoming much more common and policymakers are increasingly under pressure to take heed of them.

\section{What does expert valuation entail?}

In concept, expert valuation is deceptively straightforward. The premise is that citizens ("the public") value outcomes - such as clean air and water, reduced risk of flooding, pleasing vistas, and the survival of wildlife - with sufficient consistency that experts can gauge these values. In most cases, these values can be expressed with a common metric (most conveniently, by monetizing them), such that these values and other values, like the costs of making such improvements, can be compared. The conventional methods are based on two premises. First, the basis for the so-called "revealed-preference approaches" is that people take actions, for instance paying more for houses in areas with more trees or cleaner air, or traveling at greater expense to a park with particular amenities lacking in more accessible parks, that can be analyzed to reveal their values. The second premise is the basis for the so-called "stated-preference approaches," where economic transactions are thought to miss out on registering how people might value ecosystem elements - where even indirect 
purchases of ecosystem amenities are not relevant, as with public goods or non-use values (e.g., valuing biodiversity in areas where individuals may never visit) - people will give meaningful answers if asked how much they would be willing to pay for improvements, or how much they would be willing to accept to give up amenities. Together, these revealed-preference and stated-preference approaches, with numerous variants, constitute the conventional toolkit of expert valuation. It is a matter of "expert valuation" in that the procedures require experts to do the economic analysis to tease out the revealed value of each ecosystem element, or to devise the stated-preference questionnaires to impart the least possible bias in the responses.

When valuation is used for choosing among policy options, an additional and crucial requirement is that the consequences of policy options have to be identified. Valuation requires forecasts of consequences, and although the forecasting is not valuation per se, it is part of the analytical package that goes to policymakers. Just as certain types of outcomes are more difficult to value, some are more difficult to forecast. When values are to be applied to new cases for which valuation studies have not been conducted, the experts have to determine which estimates of values found in particular contexts are transferable to another (so-called "benefits transfer").

Expert valuations are applied to two types of environmental policies: regulations that restrict activities that threaten the environment (e.g., restrictions on or penalties for air pollution or pesticide use), and public investments to enhance environmental quality (e.g., expanded nature preserves). The benefits are largely the environmental amenities and the costs avoided from preventing environmental degradation (e.g., health and work-absence costs). The costs are largely economic in the conventional sense: investment costs (reflected in higher taxes) and forgone economic activity. Thus valuation contributes to rule-making (e.g., EPA regulations and U.S. Forest Service restrictions on National Forest uses) as well as to budgeting (e.g., authorizations for land purchases).

The conduct of expert valuation is often influenced by guidelines for "acceptable" valuation and decision rules specified by government agencies that use or oversee the analyses. Any deviation from the legislation, executive orders, or other guidelines may be ammunition for litigation by the opponents of subsequent rules or actions, especially in the highly litigious environmental policy arena in the United States. As mentioned above, in the United States OIRA has established very explicit guidelines for benefit-cost analysis, requiring that valuations be monetized as much as possible (OIRA, 2003). Nevertheless, applied valuation experts also have considerable discretion over how far to go, especially in assessing non-use values, and in the format of presentation, particularly with respect to which aspects to present as most reliable.

It is important to note that valuations can be used in several different kinds of decision frameworks. While benefit-cost analysis requires valuation, valuation does not presume that the values derived form the analysis will be used in a benefit-cost framework. For example, cost-effectiveness analysis, which takes as its starting point that particular benefits are to be sought, still must use valuations of the costs implied by the alternative policies to pursue these benefits. Another example is "habitat equivalency analysis" (HEA), required by the National Oceanic and Atmospheric Administration (NOAA) under the 1980 Comprehensive Environmental Response, 
Compensation, and Liability Act (CERCLA). To determine marine and coastal damage penalties, CERCLA begins with the requirement that those responsible for degrading an ecosystem through oil spills or other damages under NOAA jurisdiction must pay to restore or transform a larger land area to the same type of ecosystem, the size being large enough to provide the same time-discounted utility to society as if the damage had not occurred (U.S. National Oceanic and Atmospheric Administration, 2000). This approach calls upon valuation to ensure that the benefits are equivalent, but in requiring the replacement of the ecosystem, HEA does not conform to either benefit-cost analysis or cost-effectiveness. The costs of replacement may be greater than the benefits, and there may be more cost-effective ways of providing the same level of benefits than replicating the pre-existing ecosystem.

\section{Presentation of the analysis}

As valuations are fed into the decision analysis, the analysts have three options for presenting elements of presumably different degrees of certainty. First, best-estimate valuations of all elements can be aggregated and presented as an overall point estimate. This approach is universally condemned by the academics and research-institute experts engaged in developing valuation and benefit-cost methodologies, because it does not convey the degree and nature of uncertainty. The second approach is to present this aggregation with confidence intervals and other indications and explanations of relevant uncertainties. The third approach is to partition the analysis into a "core" estimate, based on the benefits derived from what the analysts consider to be the most reliable analysis, and relegate additional value derived from the presumably less reliable methods to separate addenda to the valuation.

This third approach is very common. For example, a hedonic pricing analysis, drawing inferences from actual purchases of properties with different environmental amenities, is often presented as the core valuation analysis. Additional, non-marketed ecosystem benefits, such as existence values, may be inferred from surveys (often the "contingent valuation" approach), but they are often presented as subsidiary considerations. Some of these additional benefit considerations may be monetized, but others frequently are not. These "icing on the cake" factors will be invoked to bolster a benefit-cost analysis that shows that an environmental rule or project is worthwhile (i.e., the rule or project is shown to have greater benefits than costs according to the core estimate), and the additional factors (if they are invoked at all) reinforce this conclusion. An example of this partitioning can be found in the U.S. Environmental Protection Agency's background analysis to support more stringent restrictions on NOx emissions:

Present analytical tools and resources preclude EPA from quantifying the benefits of improved forest aesthetics in the eastern U.S. expected to occur from the NOx SIP call. This is due to limitations in our ability to quantify the relationship between ozone concentrations and visible injury, and limited quantitative information about the value to the public of specific changes in visible aesthetic quality offorests. However, there is sufficient supporting evidence in the physical sciences and economic literature to support the finding that the proposed. . .call 
can be expected to reduce injury to forests, and that reductions in these injuries will likely have a significant economic value to the public (U.S. Environmental Protection Agency, 1998: 4-59).

By neglecting some aspects of averted damage to forests, as well as other nonmonetized benefits, the benefit-cost analysis was not decisive in terms of whether the annual benefits (estimated at between \$204.1 million and \$350 million) were indeed greater than the estimated annual costs (estimated at $\$ 335$ million).

In some instances, the considerations that are not rigorously monetizable are simply excluded from the summary tables that balance benefits against costs. For example, the analysis that EPA valuation experts undertook as part of the Regulatory Impact Analysis for the 2002 Concentrated Animal Feeding Operations (CAFO) regulations cited a large number of environmental improvements that stricter regulations of largescale livestock and poultry operations could produce, but they excluded many benefits from the quantitative benefit-cost analysis. The Benefits Report stated that:

It is important to note that EPA's analysis does not attempt to comprehensively identify and value all potential environmental changes associated with proposed revisions to the CAFO regulations. Instead, the Agency focuses on specific identifiable and measurable benefits. The impacts of the regulatory proposal likely include additional benefits not addressed in these analyses, such as improved recreational opportunities in near-coastal waters...; improvements in commercial fishing; improvements in near-stream activities; and non-water related benefits, such as potential reductions in odor from waste management areas. In light of these limitations, EPA believes that the benefits quantified in this report represent a conservative estimate of the total benefits of the revised CAFO standards (U.S. Environmental Protection Agency, 2000).

While the annual costs are calculated at $\$ 830.7$ million to $\$ 930.4$ million, the reported annual benefits are in the range of only $\$ 145.5$ million to $\$ 182.3$ million. Because the Clean Water Act does not require benefits to exceed costs, this analysis did not prevent the rule from being enacted. However, the neglect of the other benefits certainly did not help in the ongoing efforts to press for more effective regulation of the feeding operations. Many believe that in light of the pollution caused by flooding of CAFO waste lagoons in the late 1990s, the leniency of the Rule came as a relief to the livestock and poultry industries. ${ }^{2}$

Use of valuations by policymakers

Once the valuations and decision analyses are in the hands of policymakers, they have to decide how much credence and weight to give them. Of course, policymakers will often make their decisions on the basis of considerations quite apart from the analysis, but in many cases the analysis does constitute a constraint on the policymakers, insofar as a policy choice that runs counter to the implications of the analysis is vulnerable to the criticism that it does not further the public interest. To the degree that policymakers are motivated to take expert valuation into account, their perceptions of the credibility 
of the valuations come into play. The relevance of these perceptions is tempered by the tendency to put faith into analyses that conform with the policymakers' preconceptions and preferences.

\section{Who are the valuation experts?}

Who are the experts involved in the development and application of expert valuation? Four modestly overlapping sets of experts are involved. One consists of the theorists and ideologues who argue over the legitimacy of particular forms of benefit-cost analysis and of particular conceptions of value. The works of these individuals, typically situated in research universities, are invoked by those who apply valuation techniques and benefit-cost frameworks.

As important as this discourse is among a small number of theorists, the bulk of the effort in developing valuation methods is a matter of technical development, undertaken by the second set of experts: a few hundred individuals predominantly in North America and Europe. In the United States, these experts understandably accept the current reality that the OIRA requires formal benefit-cost analysis. Therefore this second set of experts devotes its efforts to refining the techniques of environmental valuation to fit within conventional benefit-cost analysis. Much effort has gone into trying to offset the bias toward exaggeration of the stated-preference approaches. ${ }^{3}$ Yet there are also thorny technical issues with revealed-preference approaches that have been addressed: what forms of models to use, which interest rate to use, how to accommodate the fact that choice options are often not continuous, and so on. ${ }^{4}$

The third set of experts involved in the valuation effort are those who undertake, on a case by case basis, the applied forecasting task of projecting the consequences of alternative policy options. ${ }^{5}$ At first blush, the forecasting task would seem to be reserved for natural scientists and engineers, i.e.., those with credentials to forecast the changes in concentrations of pollutants, wildlife populations, etc. Yet insofar as the effects of policies depend on implementation and compliance, other specialists such as lawyers, political scientists, and psychologists may be required as well.

The fourth set of experts is comprised of those who are engaged in determining how much the relevant stakeholders value gaining the expected benefits or avoiding the expected costs. This case-by-case application has been dominated by economists, but this role is also contestable in terms of appropriate specializations, in that the task of gauging how much the stakeholders value particular aspects - and which stakeholders are relevant - may also be undertaken by psychologists, philosophers, or political scientists.

\section{Dilemma 1: Will valuation and benefit-cost analysis supplant democratic expression?}

The first dilemma is that in trying to express environmental values, expert valuation may supplant civic activism, the expression of citizens' policy preferences, and the assertion of environmental rights. The ideological basis for dismissing or 
downgrading these modes of expression was developed with the rise of formal benefitcost analysis.

While it is unnecessary to recapitulate the lengthy debate over benefit-cost analysis $^{6}$, it is important to explore how the advocacy of benefit-cost analysis and its underlying principles drive some of the demands for particular forms of expert valuation. As a formal decision-making procedure, benefit-cost analysis presumes that relatively stable values are held by the relevant stakeholders. The most generic notion of benefit-cost analysis - that decision-makers should simply consider the benefits and costs of possible options - could accommodate exploration of the widest range of estimations of benefits and costs for each option. Yet formal benefit-cost analysis, in calling for a summary measure, requires a specific value or distribution of values for each benefit or cost. This requirement challenges the standing of the values that emerge from changing attitudes resulting from promotional efforts. For example, one component of the benefit of cleaner air arises from better health and lower medical expenses - both fairly stable outcomes for a given improvement - but the additional component arising from people's appreciation for clearer vistas, their belief in the civic duty of providing cleaner air for future generations, and the other less tangible aspects may vary considerably over short periods of time in the face of advocacy campaigns by environmental groups trying to raise consciousness over air pollution concerns. If a company proposes to build a factory with significant air pollution potential in a particular community, the concern over clean air may well rise, also changing the value that people would attribute to these less tangible elements, or the consideration of the jobs that the new factory might bring could downgrade the environmental concerns. The crucial implication is that the promotional process involved in advocacy for any given environmental or conservation initiative, insofar as this process can lead to changes in how much individuals appreciate ecosystem elements or the costs of enhancing these elements, is a threat to the formal benefit-cost decision-making framework.

This is why the most zealous advocates for the dominance of benefit-cost decision framework, such as Kenneth Arrow, Herman Leonard, and Richard Zeckhauser, regard as a virtue the fact that the conventional valuation techniques sample behaviors and survey choices that are removed from "politics." Marc Sagoff (2004: pp. 177-178) points out that some of the most extreme advocates for the primacy of benefit-cost analysis indeed pose it as a counter to politics: politics is condemned as unpredictable (Leonard and Zeckhauser, 1986: p. 34), subject to compromise and the pursuit of partisan advantage (Field, 1997: p. 19), and overly swayed by the views of policy activists (Arrow et al., 1996: p. 222; Loomis, 2000: p. 343). Arrow et al. (1996: p. 222) argue that:

Whenever possible, values used to quantify benefits and costs in monetary terms should be based on trade-offs that individuals would make, either directly or, as is often the case, indirectly in labor, housing, or other markets. Benefit-cost analysis is premised on the notion that the values to be assigned to program effects - favorable or unfavorable - should be those of the affected individuals, not the values held by economists, moral philosophers, environmentalists, or others. 
Note the dismissal, if not condemnation, of activism. Citizen participation, other than having one's value preferences ascertained by experts, distorts the aggregation of value preferences, which, by this conception, is the true guide for optimal decisions. Note also the narrowness of the concept of standing: "affected individuals" - which would seem to exclude or at a minimum downgrade the importance of non-use values.

Other theorists reject this anti-politics stance as both unjustified and quixotic. Mark Sagoff (2004: Ch. 8) has argued that this position is strikingly non-reflexive: it fails to see that the application of benefit-cost analysis conveys the values of economists, such as the primacy of individual utility maximization, a consequentialist rather than deontological ethics, and the irrelevance of activism as an indication of intensity of commitment (i.e., environmentalists' attitudes are to be discounted, even though environmentalists are citizens). Most fundamentally, this position rejects the legitimacy of the promotional function of the policy process, even though none of the conventional valuation approaches can ever be determined in a promotional vacuum. Sagoff (1994: p. 136) argues that "[1]ike actual markets, democracy does not take preferences as they come but alters them; for example, it subjects them to public scrutiny and debate....The values emerging from democratic decision-making are supposed to differ from those entering it; the capacity of political debate to transform views even lends legitimacy to the political process." Similarly, the economists Shabman and Stephenson argue that values are, and should be, shaped by the policy discourse: "When residents enter the polling booth, they face the similar [willingness to pay] question not as a purchaser of reduced flood risk, but as a city citizen. This makes the search for a 'true,' 'correct,' or 'unbiased' benefit estimate a futile one. Indeed, different benefit estimates from different techniques are not to be explained away, they are to be expected." (Shabman and Stephenson, 1996: p. 444).

The anti-politics position not only devalues activism, it also denies standing to the policy preferences of stakeholders. Conventional valuation techniques do not seek to know what policies citizens prefer, but rather how possible consequences of policies may be valued. For policy scientists working within the Lasswell-McDougal tradition, the appropriate aim of public policy is to come to authoritative decisions "by which the members of a community clarify and secure their common interests." (Lasswell and McDougal, 1992: p. xxi). The crucial question, and therefore a fundamental distinction among vehicles for expressing public preferences, is whether authoritative decisions ought to heed the community's efforts to clarify and secure common interests. Thus the risks posed by expert valuation to democratic participation are that the personal and institutional interests of the experts may clash with the public's preferences. Moreover, the input may not reflect the public as members of a community interested in expressing community values and policy preferences, but rather treats the public as passive recipients of benefits or costs as assessed by the experts. Additionally, the methods may isolate the preferences for environmental outcomes from other factors that the public may wish to take into account.

Consider the following example. Citizens may find numerous ways to express their desire for forested areas. A bond that could finance the purchase of open space with trees could be considered, as could restrictions on cutting in public forest or subsidies for the purchase of seedlings. But conventional valuation gauges preferences for trees, not the proposed means to increase their number. In this sense, the content of citizen 
input is impoverished, as compared to participation in public hearings, voting on referenda or initiatives, and so on.

In addition to devaluing the alternative channels of expressing citizens' policy preferences, formal benefit-cost analysis devalues the assertion of environmental rights. Benefits and costs of finite magnitudes also run counter to the logic of demands couched as rights. Inasmuch as the assertion of rights is a form of demand that denies the relevance of benefit-cost analysis, such an assertion cannot be represented with a finite valuation. In essence, an assertion of rights is a denial that benefit-cost analysis is relevant: "We can do X, or be protected from Y, no matter what the consequences." Of course, constitutions, laws, and practices can recognize certain rights at one point in time and not in another, and can circumscribe rights (e.g., the right to free speech, but not to incite to violence). Nevertheless, at any point in time rights are recognized that are honored through public policy even if the costs outweigh the benefits. For instance, in creating the Clean Air Act of 1970 and the Federal Water Pollution Control Act of 1972 Congress explicitly rejected a benefits-cost approach to goal setting. Instead, the Clean Air Act prioritized the protection of human health, and the Federal Water Pollution Control Act emphasized achieving fishable and swimmable water quality without consideration of the benefit-cost balance.

It is crucial to note that despite the antagonism between formal benefit-cost analysis and the logic of rights, there is nothing fundamentally antagonistic between the use of valuation and the recognition of rights. Consider two alternative methods that give standing to ecosystems or non-human species. First, as mentioned earlier, the Habitat Equivalency Analysis required by NOAA entails valuation in the service of determining how much habitat must be restored or replaced; the valuation is employed to determine how much more habitat is required to provide human benefits equivalent to offset the losses due to depriving people of immediate benefits, yet the logic of this doctrine is that the ecosystem represented by that type of habitat (e.g., wetland) has standing to be restored or replicated. The U.S. Endangered Species Act (ESA) similarly accords standing to specific species, and by extension the ecosystems in which they live, by prohibiting development that would lead to the collapse of any identified species. In the case of the ESA, technical valuation may be employed to determine the most cost-effective way of preserving the endangered species, but human valuation is not the driver or the objective of the policy.

Now, one can say that the doctrines of habitat equivalency and endangered-species protection both reflect prior consideration of benefits and costs by the executive and legislative branches - and their constituents. Thus one could construe these approaches as simply the implementation of prior decisions based on human valuation that ecosystems or non-human species ${ }^{7}$ are so important that the benefits of their preservation will outweigh any possible future costs. Nevertheless, once the decision rule has been adopted, the benefit-cost analysis is suspended. Although the human costs of a species extinction, along with the ecosystem degradation it would reflect, cannot be estimated with any degree of certainty, in principle the costs of the prohibition can greatly outweigh the benefits to people. The species and the ecosystem have the equivalent of "rights," in the sense that insofar as the ESA is honored, they are entitled to protection regardless of the costs to human society. 


\section{Dilemma 2: Will the refinement of expert valuation still leave the ecosystem under-valued?}

One possible unfolding of the rise of expert valuation is that as the methodologies become more refined, expert valuation will become more entrenched, but the weight of environmental considerations will remain less than they deserve and less than what would be conveyed by other modes of democratic expression. The risk is that methodological refinement elevates the standing of expert valuation techniques to the point of further eroding the other modes of asserting environmental considerations, without adequately capturing the full range of eco-system values. This could occur for two reasons. First, each major branch of the conventional valuation approaches has its intrinsic limitation: the revealed-preference approaches have the limitation of capturing only private utility; the stated-preference approaches cannot fully secure their credibility because of their reliance on hypothetical responses. The revealedpreference approaches are therefore likely to continue to be favored, despite the underrepresentation of public goods and non-use values. A more optimistic counter-scenario is that the refinement of expert valuation techniques, especially the stated-preference approaches, will become sophisticated enough to enable the less tangible ecosystem elements to be sufficiently and credibly represented, so that these elements are taken into account with the same standing as the economic costs. This could be reinforced by more intensive use of actual public decisions such as referendum and initiative votes (discussed in a further section of this article), both to legitimize the valuations derived from it and to validate stated-preference results using voting outcomes as the benchmark.

Second, the perceived rigor of revealed-preference approaches, consistent with the professional interests of the applied valuation experts, exacerbates this privileging of the revealed-preference approaches. There is a striking discrepancy between the proliferation of articles on stated-preference approaches ${ }^{8}$ and the secondary status that stated-preference results are typically accorded in applied valuation efforts. Thus Douglas Hall, Deputy Administrator of the U.S. National Oceanographic and Atmospheric Agency, stated in 1995 that "while we firmly believe that CVM [contingent valuation method] is a reliable economic tool, it has been seldom used and is of less significance to the natural resource damage assessment process than the debate regarding it would indicate." Shabman and Stephenson (1996: 446) account for the under-use of stated-preference approaches by noting that "only when a reasonable consensus and confidence develops among decision makers over the usefulness of any technique will the technique play a significant role in the collective choice process." The constraint comes from the fact that the decision makers typically form their judgments on technique on the basis of signals from the experts.

Contrary to the vision of the strongest advocates of the formal benefit-cost framework, the professional and institutional values and interests of the applied valuation experts shape the data gathering, interpretation, and presentation. The risks to environmental protection are that the credibility and standing of experts involved in valuation may depend on limiting the estimation of environmental and conservation value to the most technically defensible revealed-preference approaches, often limited to assessments of private individual utility. Applied valuation experts have little 
incentive to risk their own credibility and professional standing by pushing for full recognition of more controversial valuation techniques designed to capture the entire range of environmental values.

This does not mean that simple selfishness drives the reluctance to push for these more controversial techniques. As is common with modernizing intellectuals, professional standing serves the dual purpose of enabling them to be effective in the policy process as well as rewarding the expert. The self-demand on the modernizing intellectual is to be scientific, to gain respect among peers, to have an important role in shaping societal values, and to contribute to progress. Valuation experts of all four categories are modernizing intellectuals of "mid-elite" status in terms of political influence. Modernizing intellectuals do not seek direct political power, but rather intellectual and, in some cases, policy impact. They generally accede to the existing power structure. As Harold Lasswell (1965: p. 91) noted, "So long as enlightenment and skill continue to depend upon political power for values of any kind - and it is not easy to imagine a world free of politics - intellectuals will find themselves caught in the net of interlocking interests." Thus it is certainly understandable that valuation experts, even those working at the most theoretical level, by and large accept the project of trying to refine the methods within the conventional revealed-preference and stated-preference paradigms. They can always say that the regulatory environment requires them to work with the methods that will pass muster with the regulatory authorities (in the United States, specifically the Office of Management and Budget). The importance of this conformity is strongly reinforced by the litigious context, in which any valuation approach that is not defensible as rigorous can be attacked in court. The financial stakes are often certainly high enough to trigger law suits. For example, the U.S. Environmental Protection Agency and the U.S. Forest Service are constantly in court defending their restrictions. Unless the valuation methods are defensible, the parties restricted by proposed regulations will prevail.

To this end credibility concerns sway judgments to err on the side of certainty. The American legal system paces great emphasis on certainty, as opposed to creating space for uncertainty to be considered. The approach more prevalent in Western Europe, in contrast, utilizes concepts such as the precautionary principle and the principle of proportionality in regulatory policymaking, giving greater weight to uncertainty associated with risks, benefits and costs (Christoforou, 2004). In the United States there is an inherent conservatism in a system so dependent on scientific certainty. Experts are penalized for overreaction to false positives (environmental risks thought to be harmful that turn out to be minor), while there is less professional risk in under reaction to false negatives (environmental risks thought to be safe, but turn out not to be so).

As "intellectuals caught in the net of interlocking interests," the applied valuation experts need not see any conflict or ethical dilemma in relegating the less tangible ecosystem benefits to secondary status that would have less impact on decisionmakers. The progress is expected to develop out of methodological innovation, on both the theoretical and applied levels, not from challenging legislation or executive orders. It is largely up to activists, legislators, agency heads, legal experts, and those engaged in formulating alternative approaches to valuation to press for legislation, regulations, methods, and legal doctrines that will permit more space for citizen activism and greater appreciation for eco-system values. 


\section{An alternative}

The use of actual decisions in the form of initiative and referendum votes provides one alternative to address the democratic and ecosystem under-valuation dilemmas. It is striking that all four types of valuation experts have virtually disregarded the results of actual referendum and initiative votes, which provide an obvious source of valuation estimates avoiding both the neglect of public regardedness and non-use values of the revealed-preference approaches, and the tendency of stated-preference approaches to yield exaggerated environmental values because of the hypothetical nature of the questions. Initiative and referendum proposals also have been vetted through more democratically robust processes. Hundreds of initiatives (ballot measures proposed by citizens) and referenda (measures placed on the ballot by a legislative body) have been presented to municipal, county, provincial, state, and national voters to establish conservation and environmental policies. The initiatives and referenda propose environmental benefits (e.g., cleaner air or protection of biodiversity), and specify the costs (e.g., higher taxes or unemployment) of regulations, conservation investments, and so on. The costs are typically already monetized; therefore the specified benefits can be valued according to how much the public officially decides to pay. For example, the 1989 Roanoke, Virginia referendum proposed a $\$ 7.5$ million bond issue to cover the city's share of a flood protection project to be undertaken by the U.S. Army Corps of Engineers. The proposal was to increase the utility tax throughout the city; the costs were estimated to be $\$ 24$ per household annually for fifteen years. ${ }^{10}$ While some initiatives and referenda would not be terribly useful for analysis, because they combine multiple measures or extraneous issues that cannot be disentangled, scores of environmental initiatives and referenda have featured single, straightforward environmental measures and clear costs. Yet they have never been used directly to assess environmental valuation, even though numerous studies have used the results of actual initiatives and referenda to "validate" efforts using the conventional approaches, especially the contingent valuation method (List and Gallet, 2001; List and Shogren, 2002; Murphy et al., 2003; Schläpfer, Roschewitz and Hanley, 2004; Shabman and Stephenson, 1996; Vossler, Kerkvliet, Polasky and Gainutdinova, 2003), and a few studies have examined initiatives and referenda to determine what socioeconomic characteristics correlate with support for environmental initiatives (Deacon and Shapiro, 1975; Kahn and Matsusaka, 1997).

What is deterring valuation experts from using actual voting outcomes to attribute value? Surely not face validity, since the outcome has inherent legitimacy as the public's actual choice, thereby avoiding the problems of hypothetical choices; and it incorporates public-regardedness to whatever degree the voters are moved to go beyond their own self interest. Surely not a lack of useful information concerning the distribution of valuation, because a close initiative or referendum outcome also defines the valuation of the median voter, and a strong victory defines the floor on the community's value of the proposed benefits.

One possible answer is that initiative and referenda results do not conform to the justifying ideology that posits that an apolitical assessment of aggregate utility is more appropriate. The first objection would arise from the anti-politics premise that there are true values, which can be gauged through economic behavior or carefully 
sanitized surveys; an active, politicized policy process that puts measures before the electorate would only distort these "true" valuations.

The second objection would be that referendum and initiative results do not necessarily maximize aggregate utility of voters, let alone all stakeholders. For example, assume that each taxpayer would have to contribute $\$ 100$ in taxes for an open-space project. If $51 \%$ of voters believe that their $\$ 100$ tax contribution would bring $\$ 120$ of value in the benefits of open space, while $49 \%$ of the voters see their $\$ 100$ tax contributions as bringing zero value, then the aggregate benefit across voters would be negative $\$ 89.80$ per taxpayer. The minority opponents have greater "intensity," at least as measured by their felt loss of $\$ 100$ per taxpayer, compared to the lesser "intensity" of the majority supporters, who feel a more modest net gain of $\$ 20$ per taxpayer.

Thus the conventional valuation approaches operate on the premise that intensity should be reflected by aggregating revealed or reported eagerness to pay, not by willingness to participate in the initiative or referendum vote, and not by a policy process that might heighten or dampen intensity through the strategies of policy activists. Of course, many other conceptions of the public good have equally respectable pedigrees. One strand emphasizes the virtue of outcomes reached by the community, as the Sagoff and Shabman-Stephenson arguments illustrate. Another emphasizes the virtue of distributional rather than aggregate-value-maximizing norms. For example, a Rawlsian conception would argue for a policy whose outcomes bring the distribution of benefits closer to what people operating under the "veil of ignorance" as to their own standing would regard as the fairest outcome. ${ }^{11}$ Such outcomes do not necessarily reflect the greatest aggregate utility in practice. More recently, conceptions of environmental justice emphasize reducing the vulnerability of marginalized people to environmental hazards (e.g., Bullard, 1990). Although some of the proponents of benefit-cost analysis acknowledge the importance of the distributional issue (Arrow et al., 1996) there is a notable lack of attention in the valuation literature and methodology to how distribution can be addressed.

Another possible reason why valuation experts have been basically uninterested in deriving values from referenda and initiatives is rooted more in role conceptions than in ideology. An initiative or referendum result is a "just-so story." If the valuation derived from the analysis is applied to later decisions in the same community, then the valuation expert really has little to do; if it is applied to decisions for other communities, then the only question is what metric to use in the benefit-transfer mode. The referendum or initiative result, as another input that can be conveyed as "scientific" in requiring technical analysis to derive the median value of the proposed eco-system improvements, is a rival to the conventional aggregate-utility results.

\section{Conclusions}

With this article, we have tried to re-orient the problem definition concerning the implications of expert valuation of environmental benefits and costs. The prevailing problem definition, that revealed-preference and stated-preference methods need to be refined to capture more of the ecosystem benefits, ought to be greatly expanded to 
the challenge of how valuation can contribute to a set of more democratic processes that will allow an active public to bring to bear a broader range of considerations - rights, public-regardedness and community preferences for specific policies. We have seen that expert valuation itself can be applied more broadly to take advantage of public choices, and that valuation does not presuppose formal benefit-cost analysis to be useful in environmental policy deliberations.

None of the themes involved in the dilemmas of expert valuation is new. The controversies over Jeremy Bentham's proposals for the primacy of aggregate utility, and Edmund Burke's insistence on trustee representation rather than delegate representation, date back to the 18 th Century, as does the rise of science and the contestation over the political role of scientists (Armytage, 1965). The novel aspect of the particular configuration that marks the rise of expert valuation is the paradox of methodological developments intended to convey public preferences and enhance environmental considerations, which may have the opposite results on both counts. The incentives of most experts in all four categories are compatible with the current developments in expert valuation, and the rise of other concepts of valuation, or other modes of approaching the valuation task, could threaten their legitimacy as intermediaries between "public preferences" and policymakers.

To promote changes in the relative legitimacy and practical feasibility of alternative approaches to valuation and its uses, a key question is, "Who understands the unfolding of these developmental constructs, and, in particular, the implications of the rise of expert valuation?" Regulations mandating expert valuation as an input to formal benefit-cost analysis have largely been framed as a manifestation of the conflict over how much regulation is appropriate, rather than how public input shapes regulation. Moreover, the balance of expertise continues to tilt in the direction of the experts - the increasing specialization of the modernizing intellectual reduces the non-specialist's capacity to judge the validity and implications of experts' methods. ${ }^{12}$ Therefore, it seems likely that awareness of the dilemmas outlined above is quite low.

The next question, then, is "Who should be sensitized, and how?" This is equivalent to asking who has some influence over shaping the use of benefit-cost analysis and other environmental-policy decision rules, and the technical requirements for valuation inputs. Given that in the United States, the mandates to deviate from applying conventional benefit-cost analysis are established through legislation (e.g., the Endangered Species Act [ESA] and the Comprehensive Environmental Response, Compensation, and Liability Act [CERCLA]), expanding the opportunities to use valuation methods beyond the conventional techniques tied to formal benefit-cost analysis is likely to require high-level legislative lobbying on the part of environmental groups. Thus far, prominent environmental organizations, such as the Defenders of Wildlife ${ }^{13}$, and conservation think-tanks, such as Resources for the Future, implicitly endorse the conventional approaches by publicizing the valuation techniques that make more progress than others in incorporating ecosystem protection, and in assisting in technical refinements of these approaches. These stances may need to be rethought. It is worth noting that compared to the prevailing Western European orientation, U.S. environmental and conservation policy is schizophrenic in the coexistence of the benefit-cost doctrine that applies to most decisions, and the disregard for benefit-cost considerations for decisions falling under the ESA and CERCLA. It 
would certainly be worthwhile for Congress and the relevant executive agencies to consider whether a more coherent orientation would be an improvement.

Another important issue is whether it is reasonable to expect that unorthodox valuations approaches will be adopted by applied valuation experts, given the pressures on them for apparent precision and rigor. These demands on scientists, as modernizing intellectuals but as mid-level elites without any sort of power base, are currently powerful disincentives to early adoption of innovations. In the United States, the question likely to be raised within government and through the almost inevitable litigation associated with major environmental decisions is whether a methodology is sanctioned in the professional literature and rigorously validated. Therefore the first two categories of valuation experts, working on the philosophical and methodological aspects of valuation, have the potential to legitimize currently unconventional approaches by stocking the literature with research reports on the results of applying these approaches.

Finally, while we have tried to be sympathetic with the practical constraints that both valuation methodologists and applied valuation experts face, nevertheless it is important for these experts to recognize the importance - and potentially problematic nature - of their roles. As Lasswell highlighted by using the term "unnamed revolution" as an alternative label for the "revolution of modernizing intellectuals," the subtlety of the rising influence of technical experts is that neither they nor others may have sufficient awareness of the their increasing importance and the implications this has for democratic expression. As Ronald D. Brunner (1997: p. 214) has pointed out, "The politics of our time are distinguished by the rise of modernizing intellectuals, including scientists. Their power base is knowledge and skill, their technique is symbol manipulation, and their net impact on human dignity is still in doubt."

\section{Notes}

1. Note that the term "elite" should not be freighted with the implication of dominant political control. The technical experts who are involved in valuation conform to Lasswell and Kaplan's definition of a "mid-elite (1950: 201) - "The elite are those with the most power in a group; the mid-elite, those with less power; the mass, least power". These conceptions of elite mean these experts have relatively more skill (of a particular type) and thereby relatively more influence over policy outcomes than the typical individual. Yet we do not mean to imply that the role of valuation experts puts them in control of the policy process: myriad individuals and agencies influence policy.

2. Quarles and Brady LLP (2003) notes that "industry has reacted favorably to the final rule."

3. The problem is that respondents may not have an incentive to be truthful, in which case the survey is labeled "incentive incompatible", either because they hope to influence the overall survey results by registering an exaggerated response (e.g., stating that they are willing to pay more for environmental amenities than they really are), or because they wish to impress the surveyor. Various approaches have been developed to improve stated-preference surveys, for instance, by providing each respondent with a single discrete choice (e.g., some respondents are asked, "Would you be willing to pay $\$ 50$ per year in additional tax to finance a new county forest reserve;" others are asked, "Would you be willing to pay $\$ 100$ per year...") instead of giving them an open or continuous choice. See Carson, Groves and Machina, 2000; and Freeman, 2003: Chapter 6.

4. See Freeman, 2003 for a thorough description of the whole range of issues.

5. Strictly speaking, valuation per se is limited to the tasks of assessing and assigning values, but the package that these analysts present to policymakers, and the credibility of this package, depends on the work of the latter two sets. 
6. See Fischer (1990). For the extreme views, see Kelman (1981) - highly critical of the benefit-cost paradigm - and Leonard and Zeckhauser (1986) - very supportive of the paradigm.

7. It should be noted that benefit-cost analysis can give standing to those with no role in making the decisions; for example, children and future generations (Whittington and McRae, 1986).

8. See Mitchell and Carson (1989), Bateman and Willis (1999), Carson, Flores, and Meade (2001), and Freeman (2003: Ch. 6).

9. Cited in Shabman and Stephenson (1996: 445-46).

10. See Shabman and Stephenson (1996), p. 433 and passim.

11. Rawls $(1971,1993$.

12. This point is elaborated in Brunner and Ascher (1992).

13. See, for example, Defenders of Wildlife (2005).

\section{References}

Armytage, W. H. G. (1965). The Rise of the Technocrats: A Social History. London: Routledge and Kegan Paul.

Arrow, K. J., M. L. Cropper, G. C. Eads, R. W. Hahn, L. B. Lave, R. G. Noll, P. R. Portney, M. Russell, R. Schmalensee, V. K. Smith, and R. N. Stavins (1996). 'Is there a role for benefit-cost analysis in environmental, health, and safety regulation?,' Science 272: 221-222.

Bateman, I. J. and K. G. Willis (1999). Valuing Environmental Preferences: Theory and Practice of the Contingent Valuation Method in the US, EU, and Developing Countries. New York: Oxford University Press.

Brunner, R. D. and W. Ascher (1992). 'Science and social responsibility,' Policy Sciences 25: 295-331.

Brunner, R. D. (1997). 'Introduction to the policy sciences,' Policy Sciences 30: 191-215.

Bullard, R. (1990). 'Ecological inequities and the New South: Black communities under siege,' Journal of Ethnic Studies 17: 101-115.

Carson, R. T., T. Groves and M. J. Machina (2000). 'Incentive and informational properties of preference questions,' http://weber.ucsd.edu/ rcarson/. Accessed August 29, 2005.

Carson, R. T., N. E. Flores and N. Meade (2001). 'Contingent valuation: Controversies and evidence,' Environmental and Resource Economics 19: 173-210.

Christoforou, T. (2004). 'The precautionary principle, risk assessment, and the comparative role of science in the European community and the US legal systems,' in Norman J. Vig and Michael G. Gaure, eds., Green Giants? Environmental Policies of the United State and the European Union. Cambridge, MA: The MIT Press, pp. $17-52$.

Deacon, R. and P. Shapiro (1975). 'Private preference for public goods revealed through voting on referenda,' American Economic Review 65: 943-955.

Defenders of Wildlife (2005). 'A bibliography of economic valuation literature,' Conservation Economics Program http://64.233.187.104/search?q=cache:IuGeebgUn9AJ:www.biodiversitypartners.org/econ/ images/Defenders\%2520of\%2520Wildlife\%2520Economic\%2520Valuation\%2520Bibliography_0305.pdf+bibliography+\%22ecosystem+valuation\%22\&hl=en. Accessed on June 25, 2005.

Field, B. C. (1997). Environmental Economics: An Introduction, 2nd edn. New York: McGraw-Hill. Fischer, F. (1990). Technocracy and the Politics of Expertise. Newbury Park, CA: Sage Publications.

Food and Agriculture Organization of the United Nations (2000). 'Applications of the contingent valuation method in developing countries,' Economic and Social Development Papers. http://www.fao.org/DOCREP/003/X8955E/x8955e01.htm. Accessed on June 25, 2005.

Freeman, A. M. (2003). The Measurement of Environmental and Resource Values, 2nd edn. Washington, DC: Resources for the Future.

Kahn, M. E. and J. G. Matsusaka (1997). 'Demand for environmental goods: Evidence from voting patterns on california initiatives,' Journal of Law and Economics 40: 137-173.

Kelman, S. (1981). 'Cost-benefit analysis: An ethical critique,' Regulation 10: 33-40.

Lasswell, H. D. (1965). 'The world revolution of our time,' in Harold D. Lasswell and Daniel Lerner, eds., World Revolutionary Elites: Studies in Coercive Ideological Movements. Cambridge, MA.: The MIT Press, pp. 29-96. 
Lasswell, H. D. and A. Kaplan (1950). Power and Society. New Haven: Yale University Press.

Lasswell, H. D. and M. McDougal (1992). Jurisprudence for a Free Society. New Haven: New Haven Press.

Leonard, H. B. and R. J. Zeckhauser (1986). 'Cost-benefit analysis applied to risks: Its philosophy and legitimacy,' in Douglas MacLean, ed., Values at Risk. Lanham, MD: Rowan and Littlefield, pp. 31-48.

List, J. and C. Gallet (2001). 'What experimental protocol influence disparities between actual and hypothetical stated values? Evidence from a meta-analysis,' Environmental and Resource Economics 20: $241-254$.

List, J. and J. Shogren (2002). 'Calibration of willingness-to-accept,' Journal of Environmental Economics and Management 43: 219-233.

Loomis, J. B. (2000). 'Environmental valuation techniques in water resource decision making,' Journal of Water Resources Planning and Management 126: 339-344.

Mitchell, R. C. and R. T. Carson (1989). Using Surveys to Value Public Goods: The Contingent Valuation Method. Washington, DC: Resources for the Future.

Murphy, J., P. G. Allen, T. H. Stevens, and D. Weatherhead. (2003). A Meta-Analysis of Hypothetical Bias in Stated Preference Valuation. University of Massachusetts Amherst, Department of Resource Economics, Working Paper No. 2003-8.

Navrud, S., ed. (1992). Pricing the European Environment, Oslo: Scandinavian University Press.

Office of Information and Regulatory Affairs (OIRA) (2003) 'Regulatory analysis,' Circular A-4, September 17, 2003, U.S. Office of Management and Budget. Washington, D.C.: Government Printing Office.

Quarles and Brady, L.L.P. (2003). 'EPA CAFO rule faces funding dilemma and legal challenges, Quarles and Brady Environmental Alert April. http://www.qblaw.com/up_env65.asp\#Art4. Accessed on January 9, 2006.

Rawls, J. (1971). A Theory of Justice. Cambridge, MA: Harvard University Press.

Rawls, J. (1993). Political Liberalism. New York: Columbia University Press.

Sagoff, M. (1994). 'Should preferences count?,' Land Economics 70: 127-144.

Sagoff, M. (2004). Price, Principle, and the Environment. Cambridge: Cambridge University Press.

Schläpfer, F., A. Roschewitz and N. Hanley (2004). 'Validation of stated preferences for public goods: A comparison of contingent valuation survey response and voting behavior,' Ecological Economics 51: $1-16$.

Shabman, L. and K. Stephenson (1996). 'Searching for the correct benefit estimate: Empirical evidence for an alternative perspective,' Land Economics 72: 433-449.

Silva, P. and S. Pagiola (2003). 'A review of the valuation of environmental costs and benefits in world bank projects,' World Bank Environment Department Paper No. 94, Washington, DC: World Bank.

Smith, V. K., ed. (1984). Environmental Policy Under Reagan's Executive Order: The Role of Benefit-Cost Analysis. Chapel Hill, NC: University of North Carolina Press.

U.S. Environmental Protection Agency (1998). Regulatory Impact Analysis for the Regional NOx SIP Call. Office of Air Quality Planning and Standards, U.S. Environmental Protection Agency, September. Washington, DC: U.S. Government Printing Office.

U.S. Environmental Protection Agency (2000). Environmental and Economic Benefit Analysis of Final Revisions to the National Pollutant Discharge Elimination System Regulation and the Effluent Guidelines for Concentrated Animal Feeding Operation. December. Washington, DC: U.S. Government Printing Office.

U.S. Federal Register (1993). 'Regulatory planning and review,' Executive Order 12866 of September 30, 1993, U.S. Federal Register Volume 58, Number 190, October 4, 1993.

U.S. National Oceanic and Atmospheric Administration. (2000). Habitat Equivalency Analysis: An Overview. Revised October 4, 2000. http://www.osradp.lsu.edu/guide/Binder\%20A/Tab\%20B/AB3.pdf. Accessed on June 27, 2005.

Vossler, C. A., J. Kerkvliet, S. Polasky, and O. Gainutdinova (2003). 'Externally validating contingent valuation: An open-space survey and referendum in corvallis, oregon,' Journal of Economic Behavior and Organization 51: 261-277.

Whittington, D. and D. MacRae, Jr. (1986). 'The issue of standing in cost-benefit analysis,' Journal of Policy Analysis and Management 5: 665-682. 
Copyright of Policy Sciences is the property of Springer Science \& Business Media B.V. and its content may not be copied or emailed to multiple sites or posted to a listserv without the copyright holder's express written permission. However, users may print, download, or email articles for individual use. 